\title{
España entre Europa e lberoamérica en la comercialización de material escolar en el primer tercio del siglo XX
}

\section{(Spain's place in the schoolbook trade between Europe and Latin America in the first third of the twentieth century)}

\author{
M. a José MARTÍNEZ RUIZ-FUNES \\ Universidad de Murcia \\ José Pedro MARÍN MURCIA \\ Universidad Internacional de la Rioja (UNIR
}

\begin{abstract}
RESUMEN: El trabajo que presentamos parte de los catálogos de material escolar para hacer un recorrido a través del primer tercio del siglo XX. Se trata de identificar redes y trasferencias que se dibujan entre los países europeos e iberoamericanos en el mercado del material escolar: origen, desarrollo y confluencias. Una vez estudiados los agentes emisores (casas comerciales), trataremos de identificar los distintos modelos que llegan a los países receptores, qué tipo de materiales se comercializan y a qué tipo de establecimientos educativos están dirigidos entre otros indicios. Si bien el proyecto se presenta ambicioso, en un primer momento queremos hacer una valoración de las posibilidades que existen para llevarlo a cabo en toda su extensión a través de diferentes investigaciones y con la colaboración de diferentes investigadores.
\end{abstract}

PALABRAS CLAVE: Cultura material, catálogos, sistemas educativos, material escolar, editoriales.

ABSTRACT: This study of the schoolbook trade between Europe and Latin America in the first third of the twentieth century is based on an analysis of schoolbook catalogues from the time. The aim of the paper is to identify the book trade networks and exchanges between Europe and Latin America and to offer insights into the origins and development of the trade, and points of intersection between trading partners. The analysis examines the main schoolbook publishing houses, the different models of education exported, the type of material sold and the type of educational institutions at which the products were aimed, among others factors. In view of the ambitious scope of the project, we intend to explore the possibility of carrying out future phases of the research in collaboration with other researchers and research groups.

KEYWORDS: material culture, catalogues, education systems, schoolbooks, publishing houses. 


\section{Introducción}

Comenzaremos estudiando las distintas trasferencias culturales ${ }^{1}$ que se producen entre Europa y los países latinoamericanos a través de la comercialización de materiales escolares procedentes de casas comerciales europeas. El periodo comprende desde el inicio del siglo XX, momento en el que el mercado de material escolar empieza a ser un objeto comercial con circulación tanto nacional como internacional, hasta el comienzo de la II Guerra Mundial, punto este último en el que los flujos comerciales quedan suspendidos por la contienda.

Los catálogos de material escolar, utilizados como fuentes documéntales a lo largo de estos últimos años en la historiografía educativa, presentan en sus primeras páginas textos que informan de esa expansión comercial. ${ }^{2}$ El trabajo que aquí exponemos quiere servir de introducción a una investigación que de razón de ser de los flujos de material que se fueron estableciendo, los destinatarios y los usos didácticos de los mismos. Dibujar proyecciones, reciprocidades, recepciones y conexiones. Los catálogos figuran como elementos que dan lugar a la investigación, pero será necesario contar con todo un arsenal de recursos que puedan ser útiles para llevar a cabo la misma triangulando adecuadamente al información.

La identificación de recursos es un proceso que exige un tratamiento sistemático de las distintas fuentes que la historiografía educativa pone a nuestra disposición. Asimismo, la utilización de sistemas avanzados de análisis de datos como los que proporcionan el análisis cualitativo de redes ${ }^{3}$ dotarán de valor añadido a la investigación que tratamos de realizar. Para la correcta interpretación de los datos que pueden aportar las diferentes fuentes documentales hemos de utilizar las herramientas que en los últimos años han ido elaborando y difundiendo desde el ámbito de las ciencias sociales. ${ }^{4}$

Los sistemas educativos, puestos en marcha por los estados nacionales durante el siglo XIX ${ }^{5}$ se convierten, a lo largo de este periodo y tal como afirma Meda, ${ }^{6}$ en medios de

\footnotetext{
${ }^{1}$ El término trasferencia cultural ha sido asumido en los últimos años para denominar procesos en los que intervienen dos agentes. A medida que las investigaciones han tenido en cuenta procesos trasnacionales se ha constatado que, la aplicación de un modelo desarrollado en un contexto en otro diferente, comporta una trasferencia de información pero también una interpretación cultural que da lugar a un modelo diferente, un modelo que no es impuesto por los agentes que lo trasladan sino que desarrolla sus propias características. $\mathrm{He}$ aquí algunas referencias al término que podrían ser complementadas por estudios específicos sobre trasferencia cultural pero que no son objeto de este trabajo: Olivier Compagnon, "Influences? Modèles? Transferts culturels? Les mots pour le dire", América: Cahiers du CRICCAL, 33 (2005): 11-20; Michel Espagne, "La notion de transfert culturel», Revue Sciences/Lettres, 1 (2013) DOI : 10.4000/rsl.219

${ }^{2}$ Koehler \& Volckmar A.-G. \& Co., Catalogo General Ilustrado de Material Pedagógico Moderno. Material y utensilios seleccionados cuidadosamente para escuelas, Institutos y Universidades de España y de América Central y Meridional (Leipzig, Alemania: Koehler \& Volckmar A.-G. \& Co), 1928.

${ }^{3}$ Elisa Bellotti, Qualitative Networks. Mixed Methods in Sociological Research (New York: Routledge, 2015).

${ }^{4}$ Paul Smeyers and Marc Depaepe, Educational Research:Material Culture and its Representation (Swizerland: Springer, 2014).

${ }^{5}$ Gabriela Ossenbach, Corrientes e instituciones educativas contemporáneas (Madrid: UNED, 2012).

${ }^{6}$ Juri Meda, Mezzi di Educazione di Massa. Saggi di Storia della Cultura Materiale della Scuola tra XIX e XX Secolo (Milano: Franco Angeli, 2016).
} 
educación de masas. Este hecho dio lugar al nacimiento de una industria específica que trata de hacerse con el mercado que se dibuja en ese momento en el panorama educativo de los países occidentales. Con el estallido de la I Guerra Mundial la joven industria de material escolar vio como el mercado europeo tuvo serias dificultades para dar respuesta a la oferta de este tipo de manufacturas. Tras el final de la misma y con las sanciones impuestas por el tratado de Versalles, los países del bloque germánico sufrieron grandes disfunciones en sus economías, disparándose la inflación y como consecuencia, estos países tuvieron que buscar mercados alternativos para sus productos.

Los países iberoamericanos se postularon como un mercado capaz de responder a la demanda. Los sistemas educativos comienzan a configurarse tomando como modelo los puestos en marcha en Europa y Estados Unidos. España, al permanecer neutral, podía llevar a cabo labores de intermediación, no fue sometida a sanciones y por tanto pudo importar y exportar mercaderías a terceros países. Y no solo, también debemos considerar como un factor a tener en cuenta la afinidad idiomática de España con los países de habla hispana. Alemania, Francia y Estados Unidos vieron en Iberoamérica un mercado rentable. Todos ellos tenían redes comerciales establecidas en base a la industria editorial.

\section{Factores contextuales que favorecen la génesis y el desarrollo de estos mercados.}

Si nos situamos a finales del siglo XIX principios del XX, la industria del libro en castellano y sobre todo su comercialización en países iberoamericanos tenía ya un recorrido de bastantes décadas. Durante ese tiempo y tal como describen los estudiosos del tema, los distintos países europeos se posicionaron comercialmente en un mercado que resultaba para ellos atractivo y rentable. ${ }^{7}$

De forma paralela al desarrollo de las relaciones comerciales descritas, los distintos fabricantes, distribuidores, comerciales y exportadores de material destinado a la enseñanza utilizaron líneas similares, sino las mismas, de comercialización y distribución. Partimos

\footnotetext{
${ }^{7}$ Fernando Larraz, Una historia trasatlántica del libro. Relaciones editoriales entre España y América latina (19361950) (Madrid: Trea, 2010); Philippe Castellano, "Francia, España, Hispanoamérica: Estrategias editoriales ante el mercado internacional del libro (1900-1914)" Cahiers de civilisation espagnole contemporaine, 2 (2015) https:// doi.org/10.4000/ccec.5546; Ana Martínez Rus, "La industria editorial española ante los mercados americanos del libro 1892-1936", Hispania, 212 (2002): 1021-1058; María Fernández Moya, "Multinacionales del castellano. El proceso de internacionalización del sector editorial español", Revista de historia industrial, 40 (2009): 23 50; Jean-Fracois Botrel, "La cultura escrita en España (1833-1936): Balance y perspectivas", Revista brasileira de História da Mídia, 2 (2015):11-23; Jean-Francois Botrel, "Los libreros y las librerías. Tipología y estrategias comerciales", en Historia de la edición en España, dir. Jesús A. Martínez Martín (Barcelona: Marcial Pons, 2001), 135-164; Ana Martínez Rus," Comercio de libros. Los mercados americanos", en Historia de la edición en España, dir. Jesús A. Martínez Martín (Barcelona: Marcial Pons, 2001), 269-305; María Fernández Moya, "Editoriales españolas en Iberoamérica. Un proceso de internacionalización secular", ICE: Revista de economía, 897 (2009), 67-77; Pura Fernández, "El monopolio del mercado internacional de impresos en castellano en el siglo XIX: Francia, España y "la ruta" de Hispanoamérica", Bulletin Hispanique, 100 (1)(1998), 165-190; Jose Antonio Millán, "Separados por un mismo idioma, el mercado del libro español", Letras libres, 165 (2015); Béatrice HaenggeliJenni, Alexandre Fontaine et Patrick Bühler, "Une circulation des saviors pédagogiques sur papier. Revues pédagogiques, transfertset trajectoires transnationalesdes savoirs (1850-2000)", Revue suisse des sciences de l'éducation 36 (1) (2014), 11-15.
} 
del estudio de los catálogos de material escolar existentes en el Centro de Estudios sobre la Memoria Educativa de la Universidad de Murcia (CEME). Hasta la fecha se han desarrollado distintas investigaciones que utilizan en mayor o menor medida estos elementos documentales para arrojar luz sobre distintos desarrollos educativos que tuvieron lugar a lo largo del siglo pasado principalmente. ${ }^{8}$

\section{Factores generales}

Estas evidencias nos llevan a estudiar dos elementos que pudieron condicionar la génesis y el desarrollo de este mercado, sin olvidar, como apuntaremos más adelante, los lugares de producción de estos materiales y la paradoja de que fueron comercializados a través de un país que no participó de dicha industria ni de sus beneficios. Los factores a los que nos referimos son: el despegue económico de los países iberoamericanos durante el primer tercio del siglo XX, impulsado en parte por los antecedentes, desarrollo y consecuencias de la Primera Guerra Mundial y la consolidación del mercado iberoamericano del libro en castellano.

Para entender el contexto al que hacemos referencia se hace necesario atender a la descripción de determinados sucesos que subyacen al devenir de los mercados en el periodo estudiando. Aun siendo hechos generales, a veces fuera del ámbito de estudio de la disciplina que nos ocupa, su influencia en los acontecimientos que intentamos relatar fue tan importante que conviene describirlos al lector. Éstos serían los siguientes:

- La situación económica mundial y la particular de Iberoamérica.

- La I Guerra Mundial.

- La hiperinflación en Europa como consecuencia del pago de las restauraciones.

- La crisis del 29.

Atendiendo a las etapas en las que se divide la historia económica mundial, el estudio tiene lugar entre dos de ellas: la primera abarca los años 1870-1913, marcada por el inicio de la segunda revolución industrial y los cambios tecnológicos que dieron lugar a ésta representando un periodo de crecimiento generalizado; tras la Primera Guerra Mundial se dieron una serie de ajustes que buscaban recuperar el equilibrio, con un cambio en el liderazgo económico: Estados Unidos tomó el testigo de Gran Bretaña como gran potencia,

\footnotetext{
${ }^{8}$ M.J. Martínez Ruiz-Funes, "Los catálogos de material escolar como fuente para el estudio de la cultura material: la recepción y difusión del Método Froebel en España", en Patrimonio y Etnografía en España y Portugal durante el siglo XX, P.L. Moreno, A. Sebastián (eds.) (Murcia: SEPHE y CEME, 2012), 265-277; León Esteban, "Los catálogos de librería y material de enseñanza como fuente iconográfica y literario-escolar", Historia de la Educación, 16 (1997):17-46; P.L. Moreno y J.P. Marín, "La casa comercial Cultura y la oferta de Material Pedagógico Moderno en España (1924-1934)", en Pedagogía museística. Prácticas, usos didácticos e investigación del patrimonio educativo, A. Badanelli, M. Poveda Sanz, C. Rodríguez (coords.), (Madrid: Universidad Complutense de Madrid, 2014), 523-531; Marta Brunelli, "Posibles metodologías de trabajo histórico sobre la cultura material de la escuela: entre el material didáctico y los catálogos de enseñanza - Primeros resultados de una investigación en curso", en Cultura material escolar em perspectiva histórica: escritas e posibilidades V. Gaspar. G. de Souza, C. Castro (Vitória: Edufes, 2018), 181-215.
} 
este periodo entreguerras comprende los años 1918 a 1939, sin olvidar el periodo 19141918 que tiene distintas lecturas dependiendo del lugar geográfico desde el que se aborda. Éste último apunte resulta significativo de cara a definir la posición de España, un país que no participó en la contienda y por tanto se mantuvo al margen de los cambios y tensiones que afectaron a otros muchos países principalmente de Europa.

Hacia 1870 los avances tecnológicos comenzaron a ser utilizados en la industria, asimismo, el uso de nuevas fuentes de energía como el petróleo y la electricidad proporcionaron a los procesos industriales dinamismo y capacidad de producción a escala. Se redujeron costes y se incrementaron la producción y por tanto el beneficio. Por otro lado comenzó a darse una especialización productiva y una mejora en la asignación de recursos. Podemos decir que se asistía a la primera gran globalización. ${ }^{9}$

Por otro lado, el marco institucional que generó este tipo de estructuras favoreció la atracción de inmigrantes por parte de las economías en desarrollo de América y Oceanía y se generalizó el sistema internacional de pagos implantando el patrón oro ${ }^{10}$. Entendemos globalización como el proceso de creciente integración de los mercados de bienes y factores de producción (capital y trabajo). Este proceso da lugar a la generación de grandes flujos de bienes, trabajo o capital entre las economías participantes; la renta de las distintas sociedades crece y la demanda aumenta; se produce una integración de los mercados lo que lleva a una similitud de precios cuyas diferencias van a determinar la dirección del flujo de bienes y servicios y de capital. ${ }^{11}$

A largo plazo el crecimiento del comercio internacional superó a la producción mundial en el periodo 1870-1913. A Europa llegaban principalmente materias primas y exportaba manufacturas. Por otro lado, la mayoría de países presentaban una ausencia de revoluciones o contiendas. Es una etapa en la que el proteccionismo dio lugar a la imposición de aranceles. El equilibrio de precios favoreció la integración económica internacional e impulsó el proceso de convergencia de los mercados. Se desarrollaron los sistemas educativos, se abandonaron las tierras de cultivo y se produjo una especialización en el sector productivo. $^{12}$

Aparecieron los departamentos de marketing y surgieron innovaciones en los sistemas de distribución como los grandes almacenes, la venta por catálogo y correo o las cadenas de tiendas que abastecían a amplios territorios. Además, los mejores niveles salariales y una mayor seguridad en las rentas del trabajo redundaban en una mayor capacidad de consumo para una parte creciente de la sociedad. En Alemania se consolidó la industria apoyada en una política proteccionista pero sin que ello bastase para dar salida a la pro-

\footnotetext{
${ }^{9}$ Daniel A. Tirado Fabregat, "Crecimiento económico (1870-1913): Internalización y cambio tecnológico", en Los tiempos cambian. Historia de la economía, Jordi Palafox (ed.) (Valencia: Tirant lo Blanch, 2014), 141-170.

${ }^{10}$ Rafael Calduch Cervera, "La estructura económica internacional del siglo XIX" Estudios Internacionales de la Complutense vol. 8, 3 (2006): 35-81.

11 Tirado, "Crecimiento económico (1870-1913)".

${ }^{12}$ Calduch, "La estructura económica internacional del siglo XIX": 35-81
} 
ducción de su gran potencia industrial. Al mantenerse el Proteccionismo hasta 1914, la industria hubo de buscar salidas en el mercado mundial. ${ }^{13}$

Alemania se encontraba ante una situación de superproducción en el sector industrial, subconsumo relativo y superinversión. Tras la guerra los vencedores exigieron las reparaciones a los vencidos. El tratado de Versalles modificó las fronteras de los países derrotados y su capacidad productiva, sus infraestructuras y sus redes de trasporte y comercio. La inflación hizo que los precios se multiplicaran por dos en Francia, Reino Unido, Italia y Holanda, por 3 en Alemania y por 11 en Austria hasta 1920. El valor de las monedas europeas se devaluó haciendo inviable plantear el comercio sino en otra moneda menos debilitada. Aun con este panorama, a final de los años 20 el comercio mundial se incrementó en un $50 \%$ y la producción en un $25 \%$. $^{14}$

En Europa, Iberoamérica y Japón la salida del patrón oro aumentó el margen de maniobra de los gobiernos para activar la recuperación. En el resto del mundo permitió desplegar políticas monetarias expansivas y eliminar la presión deflacionista que el déficit de la balanza de pagos imponía sobre la política fiscal. Alemania fue el país en el que la depresión económica fue más grave. Los problemas de balanza de pagos y el incumplimiento de las reparaciones agravaron todavía más la situación al precipitar una crisis monetaria y bancaria. $^{15}$

Durante el siglo XIX en Iberoamérica tres cuartas partes de la población vivía en zonas rurales y tres cuartas partes eran analfabetas. No existía una estructura que posibilitase el comercio exterior y los sistemas nacionales no eran sólidos. Durante el periodo 1880-1920 el trasporte se abarató drásticamente a nivel nacional e internacional. Los años 20 fueron la década de trasformaciones institucionales. Posteriormente todos los países experimentaron graves reveses económicos con la crisis de la deuda, deteniéndose toda tendencia hacia una mejora en la distribución del ingreso, con excepción de Uruguay. Los inmigrantes se convirtieron en maestros, sobre todo en Argentina y Uruguay. En los años 20 y 30, quizá a consecuencia de la urbanización y de una mayor conciencia de sociedad, hubo un mayor avance de la enseñanza primaria. ${ }^{16}$

La demanda de exportaciones y las entradas de capital tuvieron un impacto profundo en las diversas estructuras económicas, sociales y políticas de Iberoamérica. La rápida expansión del comercio mundial fue una de las características de la aceleración del crecimiento económico. El ferrocarril y los navíos de vapor revolucionaron el trasporte de mercancías y personas de manera eficiente. Las dos guerras mundiales y la depresión de 1929 significaron para Iberoamérica tanto oportunidades como peligros. Fue un periodo de mayor crecimiento que el promedio mundial, se incrementó la demanda de exportaciones.

\footnotetext{
${ }^{13}$ José Morilla Ortíz, La crisis económica de 1929 (Madrid: Pirámide, 1988)

14 Ibidem, 102.

${ }^{15}$ Calduch, "La estructura económica internacional del siglo XIX".

${ }^{16}$ Rosemary Thorp, Pobreza, progreso y exclusión. Una historia económica de Iberoamérica en el siglo XX (Washington DC: Banco Interamericano de desarrollo, 1998).
} 
Se produjo una aceleración del crecimiento demográfico, un aumento de la población urbana y un ascenso de nacionalismos. ${ }^{17}$

\section{Factores específicos}

Una vez presentados los factores generales, se hace necesario atender a los específicos: por un lado, tenemos la afinidad lingüística y cómo se hizo patente a través del negocio editorial; y por otro el desarrollo de los sistemas educativos avalados por una nueva burguesía que demandaba la vanguardia pedagógica.

Durante el periodo que nos ocupa y los antecedentes del mismo comenzaron a ponerse en marcha los sistemas educativos en distintos países latinoamericanos. Se organizaron a final del siglo XIX dentro de unas coordenadas que más bien se parecen a las de la Europa de la primera mitad de siglo. Según apunta Ossenbach ${ }^{18}$ eran países con fuerte herencia colonial y una marcada influencia de la iglesia católica. La puesta en marcha de estas instituciones tuvo lugar a diferentes ritmos y con distintas connotaciones. Aquellos países que se modernizaron en una fase temprana presentaban una sociedad civil capaz de asumir el soporte de instituciones educativas dentro de un modelo más liberal. Por el contrario, cuanto mayor era el retraso económico respecto a los países más industrializados, mayor papel se le concedió a la intervención del gobierno para promover el desarrollo y poner reformas en marcha.

La necesidad de estructurar la educación en relación con el sistema productivo hizo que el curriculum presentase un carácter técnico. Conforme se inició el proceso de industrialización y con el fin de estimularlo muchos estados promovieron sobre todo la educación técnica. Los estados de industrialización tardía se hicieron cargo de esta educación y los países en estadios más avanzados de industrialización la dejaron a la iniciativa privada.

En Iberoamérica, al contrario que en Europa, dónde el sistema educativo se inclinó a adecuarse a unos requerimientos de status desligados del mundo práctico e industrial, la influencia de la filosofía positivista propició la introducción de materias científicas y prácticas en el currículo escolar, una mentalidad más acorde con el progreso burgués y secularización de los contenidos de la enseñanza. El pensamiento lberoamericano predominante en el siglo XIX se caracterizaba por proponer fórmulas de origen europeo para superar las asincronías o destiempos. ${ }^{19}$

El idioma, la religión común y una larga tradición colonial tuvieron un fuerte impacto en el sistema educativo. Fue la clase dominante quien organizó los nuevos estados. La actitud de estas oligarquías no impidió en muchos países el desarrollo de las clases medias en los inicios del siglo XX. La clase dominante y poder político se unieron, la población urbana se fue consolidando mediante la integración de algunos grupos rurales. La ciudad se erigió en

\footnotetext{
${ }^{17}$ Thorp, Pobreza, progreso y exclusión.

${ }^{18}$ Gabriela Ossenbach Sauter, Formación de los sistemas educativos nacionales en Hispanoamérica: el caso ecuatoriano, 1895-1912 (Quito: Universidad Andina Simón Bolivar, 2018), 48.

${ }^{19}$ Ossenbach, Formación de los sistemas educativos nacionales en Hispanoamérica: el caso ecuatoriano, 18951912, 102.
} 
centro y base del estado nacional. Las oligarquías y las clases medias asentadas en el medio urbano eran numéricamente inferiores a la población rural. La clase media experimentó un crecimiento cuantitativo y fue beneficiaria de la política educativa. Estas clases medias, afectadas por las crisis económicas iniciadas por la I Guerra Mundial, asumieron el papel destacado de la educación en la preparación y el reclutamiento de las burocracias. ${ }^{20}$

Los sistemas educativos hicieron que la clase media emergente se viera favorecida por el desarrollo de la instrucción. Las clases medias se inclinaban por los estudios jurídicos y políticos. La educación secundaria cobró importancia, sobre todo estudios comerciales e idiomas modernos. Los estudios superiores más demandados fueron los de agronomía, veterinaria y economía. Los contenidos de corte científico contribuyeron, sin lugar a dudas, a crear un talante moderno y secularizado.

\section{Las editoriales y el mercado hispanoamericano. Factores condicionantes.}

A través de distintas investigaciones podemos constatar que la edición en castellano que llegó a los mercados iberoamericanos ya en el siglo XIX, pero lo hizo utilizando diferentes itinerarios, las importaciones desde España no representaban un porcentaje muy amplio del mercado. Fueron otros países europeos los que se posicionaron como principales exportadores de este tipo de mercaderías. Larraz ${ }^{21}$ afirma que las editoriales españolas se industrializaron de una manera tardía porque eran empresas de pequeño capital familiar. A lo largo del primer tercio del siglo XX reclamaron el mercado hispanoamericano que el siglo anterior había estado dominado por empresas francesas, alemanas y norteamericanas que publicaban sus títulos en castellano. ${ }^{22}$ Editoriales situadas principalmente en Madrid y Barcelona aumentaron su producción y se encargaron de la exportación a Hispanoamérica ${ }^{23}$. Existían distintos proyectos que trataban de potenciar, desde finales del siglo XIX, las relaciones culturales con los países iberoamericanos, sobre todo tras 1998, incluidas las cámaras de comercio. Sin embargo la política arancelaria no contribuyó al desarrollo de la industria editorial. El libro español resultaba más caro en los mercados americanos que sus competidores de otros orígenes, y lo era por el precio y por la forma de pago, además la moneda española estaba sobrevalorada respecto a la de otras naciones que presentaban altas tasas de inflación. El mercado americano estaba dominado por edi-

\footnotetext{
${ }^{20}$ Ossenbach, Ibidem, 124

${ }^{21}$ Larraz, Una historia trasatlántica del libro. Relaciones editoriales entre España y América latina (1936-1950).

${ }^{22}$ Fernández, "El monopolio del mercado internacional de impresos en castellano en el siglo XIX".

${ }^{23}$ Martínez Rus, "La industria editorial española ante los mercados americanos del libro 1892-1936"; Álvaro Ceballos, "La implantación de la librería alemana en España e Hispanoamérica de 1850 a 1900", en Handeln und Verhandeln. Beiträge zum 22. Nachwuchskolloquium der Romanistik, Marina HERTRAMPF et al. (éds.) (Bonn: Romanistischer Verlag (Forum Junge Romanistik, 13), 2007), 453-472; Pura Fernández, "La editorial Garnier de parís y la difusión del patrimonio bibliográfico", Tes philies tade dora: miscelánea léxica en memoria de Conchita Serrano, (1999): 603-612; Miguel A. López-Morell y Alfredo Molina Abril, "La compañía iberoamericana de publicaciones, primera gran corporación editorial en castellano", Revista de historia industrial, 49 (2012): 111-145; Juan Miguel Sánchez Vigil, "La editorial CALPE y el catálogo general de 1923", Documentación de las ciencias de la información, 29 (2006): 259-277; Gabriela Dalla Corte y Fábio Espósito, "Mercado del libro y empresas editoriales entre el Centenario de las Independencias y la Guerra Civil española: la editorial Sudamericana", Revista Complutense de Historia de América, 36 (2010): 257-286.
} 
toriales francesas, Louis Michaud entre otras, que publicaban libros en castellano. También se posicionaron empresas inglesas y estadounidenses.

Para las editoriales francesas más importantes de finales del siglo XIX y principios del siglo XX, los libros publicados en castellano y destinados a los mercados español e hispanoamericano fueron un elemento fundamental de su éxito económico. ${ }^{24}$ Ofrecían pagos más flexibles que las casas españolas y realizaban una propaganda intensa y efectiva. Los fabricantes y editores extranjeros interesados en la introducción de sus productos en mercados americanos, incluidas publicaciones, comenzaron a trabajar en castellano y a ocuparse de cuestiones hispanas. También resultaba indispensable la distribución por parte de cada editorial de catálogos que recogiesen las publicaciones y novedades para distribuirlos en librerías, centros de educación y demás potenciales clientes. La casa Calleja fue la única que tuvo una penetración efectiva en este mercado. ${ }^{25}$

En París, a final del siglo XIX había una importante colonia española, los editores franceses interesados por nuevos mercados en los que colocar su producción, vieron la colonia como elemento importante para promover el éxito en la conquista. ${ }^{26} \mathrm{La}$ independencia de las repúblicas de Iberoamérica significó el fin de los privilegios comerciales. Algunas editoriales francesas disponían de una red de comisionistas y viajantes para conocer y abastecer el mercado del libro en esas repúblicas. El mercado español era periférico pero las repúblicas americanas estaban dirigidas por librepensadores que seguían modelos europeos, lo que facilitó la penetración en dichos mercados de estas élites europeas que buscaban nichos de negocio para sus productos. La implantación de librerías en comercio directo con Alemania fue un fenómeno nuevo de finales del siglo XIX y de desarrollo rápido: a mediados de siglo apenas puede encontrarse una sola en un país de habla hispana; en 1900, sin embargo, ya había 13 en España y 35 en toda Hispanoamérica: 10 en Argentina, 11 en Chile, 6 en México, 4 en Perú, dos en Paraguay, una en Cuba y otra en Uruguay. ${ }^{27}$ La historia de la cultura escrita en España no puede concebirse al margen de la historia de las trasferencias culturales, especialmente a través a de la prensa y el libro español producido en Francia, Alemania e Italia. ${ }^{28}$

Según afirma Botrel${ }^{29}$ la comercialización del libro a final del siglo XIX solía requerir otras actividades como la venta de objetos de escritorio que a partir de 1880 se comercializaban a través de catálogos. Fueron imponiéndose como medio para la promoción y difusión del libro a mediados del siglo XIX. Algunas librerías comenzaron a actuar como corresponsales de casas editoriales y de otras librerías. Pero el mercado exterior ibe-

\footnotetext{
${ }^{24}$ Castellano, "Francia, España, Hispanoamérica: Estrategias editoriales ante el mercado internacional del libro (1900-1914)".

${ }^{25}$ Julio Ruiz Berrio et al., La editorial Calleja, un agente de la modernización educativa en la restauración (Madrid: UNED, 2002).

${ }^{26}$ Castellano, "Francia, España, Hispanoamérica: Estrategias editoriales ante el mercado internacional del libro (1900-1914)".

${ }^{27}$ Álvaro Ceballos, "Las empresas editoriales de Jose Abelardo Núñez en Alemania, 1881-1905", Historia, 41, vol I (2008): 43-62.

${ }^{28}$ Botrel, "Los libreros y las librerías. Tipología y estrategias comerciales".

${ }^{29}$ Ibidem, 148.
} 
roamericano apenas tuvo incidencia sobre esta actividad. ${ }^{30}$ Los libreros, a principio del siglo XX dejaron de ser productores, salvo contadas excepciones. En el Congreso Nacional de Comercio en Ultramar de 1923 se estableció el libro español y su difusión como forma de penetración en este grandísimo mercado avalado por la afinidad idiomática y cultural de los países que lo conformaban ${ }^{31}$. El libro en castellano formó parte del programa de expansión económica y cultural en Iberoamérica, pero el mercado americano estaba dominado por editores franceses especializados en la producción de este tipo de libros. Aunque no solo, otras casas editoriales alemanas, inglesas e incluso americanas se posicionaron en el mercado. "En América resultaba más fácil y más barato conseguir un libro en castellano editado en París o Leipzig que en España". ${ }^{32}$ Los aranceles gravaron las materias primas y esto se reflejó en los elevados costes de los libros editados en España, por otro lado las tiradas eran reducidas. Los servicios de correos entre España, toda América y el archipiélago de Filipinas quedaron constituidas por un solo territorio postal en 1922, tránsito gratuito y franqueo igual al interior de cada uno de los países. ${ }^{33}$ Esta ventaja fue aprovechada por los editores franceses que llegaban a España por vía ferroviaria. La mayoría de las editoriales francesas tenían abiertas cuentas con los clientes americanos, lo que facilitaba el pago efectivo de cantidades, bien en su totalidad o giradas a 30,60 y 90 días. Estructuras que beneficiaban el comercio desde estos países. Algunos viajantes vieron en este mercado una oportunidad de negocio, la edición española se afianzó durante la Gran Guerra, sin embargo, posteriormente tanto Francia como Alemania recuperaron dichos mercados. Las casas extrajeras tenían sucursales establecidas en todas las capitales importantes de América. Las dificultades que acompañaban a la exportación librera revelaban la débil organización comercial de la industria editorial española en comparación con formas de hacer más modernas y racionales.

Según afirma Ceballos ${ }^{34}$ la empresa de comisión K.F. Koehler era la más importante en el mercado que estamos estudiando. También Volckmar figuraba como comisionista, lo que sugiere que la distribución internacional era una actividad subsidiaria de algunos agentes con gran volumen de negocio. Lo más frecuente era que estos establecimientos comerciaran, además de con libros y revistas, con objetos de escritorio, instrumentos musicales, patrones de moda, escapularios, premios, etc...Se trata de una característica que Botrel ha denominado polivalencia.

\footnotetext{
${ }^{30}$ Botrel, Ibidem, 160.

${ }^{31}$ Ana Martínez Rus, "Comercio de libros. Los mercados americanos", en Historia de la edición en España, Jesús

A. Martínez Martín, 281.

32 Ibidem, 283.

${ }^{33}$ Ibidem, 290.

${ }^{34}$ Alvaro Ceballos, "Las empresas editoriales de Jose Abelardo Núñez en Alemania, 1881-1905", Historia, 41, vol I (2008): 43-62.
} 


\section{La edición escolar}

La edición escolar en España, afirma Guereña ${ }^{35}$ comenzó a despegar en la época de la Restauración, los editores de manuales escolares españoles se centraron en la escuela primaria y consideraron la exportación a las repúblicas americanas de habla hispana un mercado potencial. Las editoriales más importantes dedicadas al libro de texto se concentraban en Madrid y Barcelona, alcanzando una notable expansión incluso de carácter internacional. Pero no solo, algunas de estas ediciones se publicaban también a través de editoriales en Francia, Garnier Frérès, y en América, Appelton. Vemos como Garnier asumió un papel destacado en este mercado. Otra de las casas editoriales fue Armand Colin con un importante catálogo e implicada en la renovación pedagógica francesa. Gustavo Gili también tomó parte en este mercado. La mayoría lo hizo a través de atlas y diccionarios destinados a las escuelas. ${ }^{36}$

Por otro lado, desde instancias de los jóvenes estados americanos, políticos e intelectuales como el chileno Jose Abelardo Núñez emprenden viajes a Europa con la intención de conocer de cerca las escuelas más prestigiosas del continente y poder hacer llegar a sus países de origen las innovaciones pedagógicas que se estaban ensayando en dichas instituciones. Núñez fue enviado a Europa para estudiar los avances pedagógicos y poder desarrollar un proyecto de puesta en marcha del sistema educativo chileno hacia 1883. Reclutó profesores alemanes y suizos para sus escuelas normales y se encargó de adquirir material de enseñanza ${ }^{37}$. Uno de los lugares con los que tuvo un contacto más estrecho fue Leipzig, un gran centro editorial pero también el lugar en el que se encuentran las mayores industrias de material escolar que operan en Europa durante el siglo XX.

Pero no solo Núñez desarrolló negocios en la ciudad de Leipzig con respecto a las ediciones de textos escolares en español, otros comisionistas venidos de América también desarrollaron negocios en este sentido. Por otro lado, la impresión en Leipzig era barata y de gran calidad, Chile legisló para adquirir material escolar de Europa y consignó para ello un presupuesto, encargando Núñez la adquisición de material en Alemania, Austria y Francia. Afirma Ceballos ${ }^{38}$ que el mercado editorial alemán estaba saturado, lo que provocó una especialización que empujó a los empresarios a buscar mercados en países extranjeros.

Afirma Gereña ${ }^{39}$ que los profesionales idearon estrategias comerciales como la financiación de revistas de enseñanza, boletines de novedades bibliográficas, anuncios, páginas de publicidad y catálogos. En 1910, la Gazeta del 18 de junio nos habla del intercambio de traba-

\footnotetext{
35 Jean Louis Guereña, "La edición escolar en España durante la Restauración (1875-1900)", en Centros y periferias: prensa, impresos y territorios en el mundo hispánico contemporáneo: homenaje a Jacqueline CovoMaurice, coord. Nathalie Ludec, Françoise Dubosquet Lairys (París: PILAR, 2004), 105-116.

${ }^{36}$ Castellano, "Francia, España, Hispanoamérica: Estrategias editoriales ante el mercado internacional del libro (1900-1914)".

${ }^{37}$ Alvaro Ceballos, "Las empresas editoriales de Jose Abelardo Núñez en Alemania, 1881-1905", Historia, 41, vol I (2008): 43-62.

38 Ibidem.

39 Jean Louis Guereña, "La edición escolar en España durante la Restauración (1875-1900)", en Centros y periferias: prensa, impresos y territorios en el mundo hispánico contemporáneo: homenaje a Jacqueline CovoMaurice, coord. Nathalie Ludec, Françoise Dubosquet Lairys (París: PILAR, 2004), 105-116.
} 
jos y material de enseñanza entre los establecimientos docentes de España y las repúblicas americanas y encarga al Museo Pedagógico Nacional de la gestión dichos intercambios.

\section{Los catálogos de material escolar editados en España.}

El estudio de los catálogos pretende poner de manifiesto las relaciones comerciales que se establecieron entre Europa e Iberoamérica en ámbito del material escolar. El material escolar condiciona, como afirma Marín, ${ }^{40}$ la docencia y la interpretación del curriculum, e influye en los planteamientos didácticos de las distintas disciplinas. Comenzó a ser un producto comercial con la génesis y evolución de los distintos sistemas educativos nacionales, tal como afirma Meda ${ }^{41}$ se convirtió en un medio de educación de masas. En un determinado momento, debido a factores que detallaremos, este mercado secundario, el del material escolar, empezó a construir una identidad propia, si bien no podemos desligarlo del todo de las casas editoriales matrices, sin embargo su producción y comercialización presentaban características distintivas que trataremos de poner de manifiesto.

Los catálogos de material escolar son un tipo de publicación que algunas editoriales especializadas en el mundo educativo utilizaban para publicitar aquellos artículos destinados al consumo de la escuela. En un principio ofertaban útiles de papelería, posteriormente aumentó dicha oferta con diplomas o libros de premio; con el paso de los años, el ajuar de la escuela se incrementó, con el material para la enseñanza de las ciencias como estandarte de los nuevos tiempos, objeto de una extensa oferta de material escolar. ${ }^{42}$ Todas las disciplinas en general fueron objeto de revisión didáctica, y los expertos pusieron a disposición del profesorado más vanguardista todo tipo de artefactos que facilitaban la puesta en marcha de nuevas metodologías. Elementos como el mobiliario o el equipamiento higiénico de los centros escolares era ofertado en las páginas de los catálogos que constituyen en sí mismos una foto fija de la escuela más vanguardista de la época. Unas industrias educativas cuya existencia, pervivencia y prosperidad dependía entre otros factores de su capacidad para estimular y atender una creciente demanda nacional e internacional de materiales y recursos para la enseñanza. Unas necesidades que no eran ajenas a la ley de la oferta y la demanda.

Han sido varios los estudios llevados a cabo a través de los catálogos de material escolar, la perspectiva que pretendemos exponer en este trabajo pasa por el ámbito de distribución de los materiales ofertados en los mismos. De los catálogos estudiados, todos ellos editados o publicados en español y la mayoría de ellos en España, hemos seleccionado aquellos que, de manera explícita, establecen en alguna de sus páginas, su intención de vender y/o distribuir sus productos tanto en España como en países hispanohablantes. Del total de catálogos consultados, una parte de ellos contienen, bien en el prólogo o bien en la portada o en ambos

\footnotetext{
${ }^{40}$ Jose Pedro Marín y Mํㅡㄹ José Martínez, "Categorización de los materiales didácticos para la enseñanza de los seres vicos en los antiguos gabinetes y laboratorios", Cabás, 21 (2019): 1-22.

${ }^{41}$ Meda, Mezzi di Educazione di Massa.

${ }^{42}$ Moreno y Marín, "La casa comercial Cultura y la oferta de Material Pedagógico Moderno en España (19241934)", 524.
} 
lugares, referencias expresas a la posibilidad de hacer llegar los artículos que publicitaban a los países del otro lado del Atlántico. Hemos podido constar que todos los catálogos que presentan esta característica están datados en los 30 primeros años del siglo XX.

Por otro lado tanto Alemania como Francia, de forma paralela al mercado editorial, publicaron en castellano catálogos que son representativos de la importancia de las relaciones comerciales que en el ámbito del material escolar, se establecieron entre Europa e Iberoamérica. Esos catálogos son el editado por la casa Louis Michaud de Francia, datado aunque no fechado en el año 1913 y los editados por las casas alemanas Koehler, Volckmar y la unión de ambas entre los años 1910 y $1928 .{ }^{43}$

Tenemos pues dos tipos de ediciones, aquellas firmadas por editores y libreros españoles, que muchas veces incluían en su oferta productos de empresas extranjeras: alemanas, francesas o estadounidenses, que evolucionan con el tiempo; y los catálogos referidos anteriormente: ediciones lujosas, con cientos de páginas, ilustrados con grabados y láminas centrales a color, que son indicativos de la rentabilidad de los mercados a los que iba dirigida su oferta comercial.

\section{El mercado iberoamericano. Oferta y distribución}

En una primera aproximación a las redes de distribución, vamos a estudiar las referencias de los prólogos de los catálogos. Analizaremos algunas de estas referencias y trataremos de relacionarlas con los factores que hemos descrito a lo largo de los apartados anteriores.

El primero de los catálogos es el que la librería Bastinos publicó en 1881. La librería Bastinos fue fundada en el siglo XVIII por Ignacio Estivil, en Barcelona, en 1852 pasa a denominarse Casa Bastinos. Se dedicó a la edición de libros, revistas y material escolar orientado principalmente a la enseñanza primaria. ${ }^{44}$ Hasta 1927 su actividad editorial y comercial se orientó a la enseñanza, participando del auge de los nuevos métodos pedagógicos que tuvo lugar en la ciudad de Barcelona en este inicio de siglo. El catálogo de 1881 atendiendo al orden cronológico, es el primero que presentaba referencias al mercado iberoamericano. Ofertaba "Libros y material de enseñanza propios de la casa" y aunque llevaban publicando catálogos desde 1855 este es el primero que se especializó en material escolar. En el texto del prólogo podemos leer lo siguiente:

Casa especializada en elementos para la escuela. Presentes en exposiciones de Chile, Filadelfia y París. Las publicaciones son conocidas en las provincias ultramarinas de América y Oceanía y en la mayor parte de las repúblicas iberoamericanas. ${ }^{45}$

\footnotetext{
${ }^{43}$ K. F. Koehler, Catalogo ilustrado de material de enseñanza. Lista de los aparatos y útiles más modernos y adecuados para la enseñanza objetiva, aprobados y en uso en las escuelas de Alemania. Segunda edición (Leipzig: K.F. Koehler, 1910); F. Volckmar, Catálogo General de Material de Enseñanza y Útiles para escuelas (Leipzig: F. Volckmar, 1910); Koehler \& Volckmar A.-G. \& Co., Catalogo General Ilustrado de Material Pedagógico Moderno.

44 José Bosch, Centenario de la Librería Bastinos (Barcelona: José Bosch, 1952).

${ }^{45}$ Librería Juan y Antonio Bastinos, Catálogo de los efectos y libros propios de la casa (Barcelona: Juan y Antonio Bastinos, 1881).
} 
Se utilizaba como elemento de prestigio la presencia de la casa editorial en los países de americanos, pudiendo constatar que las trasferencias culturales, no solo tienen lugar en una dirección sino que se dan en ambos sentidos. Las exposiciones universales fueron también un importante referente a la hora de publicitar estos materiales, la participación de la empresa en estos eventos era garantía de calidad de los productos que ofertaba, así podemos ver como la portada interior aparece decorada con las medallas de las exposiciones universales celebradas en fechas cercanas. ${ }^{46}$

En las condiciones de venta encontramos referencias a los mercados de ultramar, y el comerciante concedía un plazo de dos a seis meses para el pago de las facturas, dependiendo del volumen del pedido y de la localización geográfica del mismo. Informaba que el catálogo ofertaba libros y material de enseñanza tanto de casas españolas como extranjeras. De esta misma editorial hemos analizado cuatro obras más. El almanaque Bastinos para el año 1885 en el que se apuntaba que los pedidos destinados a ultramar aumentaban de precio. ${ }^{47}$ Sus productos se comercializaban en Puerto Rico, Cuba y Filipinas, provincias españolas hasta 1898 y en las demás repúblicas americanas. Esta obra no ofertaba material, pero no deja de ser un elemento de marketing ya que el almanaque se regalaba con El Monitor de Primera Enseñanza, revista a través de la cual esta casa comercial hacía llegar a las escuelas los principales avances pedagógicos del momento.

En el catálogo de 1897 aparecían en la portada los escudos de los siguientes países: en un lugar central, arriba Cuba y Puerto Rico; a ambos laterales de la página Costa Rica, Chile, Colombia, Ecuador, Salvador, Guatemala, Venezuela, México, Honduras, y en el centro abajo y destacados Uruguay y Argentina. En este catálogo Bastinos se presentaba como editor mostrando los premios que la editorial había recibido en diversos certámenes tanto nacionales como internacionales. ${ }^{48}$ En cuanto a las condiciones de venta apuntaba que si los productos eran adquiridos en ultramar, los precios eran mayores, los que indicaba el catálogo están referidos a Barcelona. Detallaba exhaustivamente las instrucciones para enviar paquetes por correo postal, recordar que el correo postal desde España a los países iberoamericanos tenía condiciones especiales. Exportaba también a Europa, según consta, la casa comercial tenía corresponsales, aunque no detallaba en qué plazas. Apuntaba que el material escolar contenido en el catálogo era el producido por casa, para los demás enseres, procedentes de otras casas nacionales y extranjeras remitía al catálogo especial de material de 1891.

\footnotetext{
${ }^{46}$ Inés Dussel, "Between exoticism and universalism: educational sections in Latin American participation at international exhibitions, 1860-1900", Paedagogica Historica, 47 (2011): 601-617.

${ }^{47}$ Joaquina Balsameda de González et al., Almanaque Bastinos para 1885 (Barcelona: Librería de Juan y Antonio Bastinos, 1884)

${ }^{48}$ Antonio J. Bastinos, Catálogo llustrado de los Productos de esta Casa. Libros y Material Escolar (Barcelona: Antonio J. Bastinos Editor, 1897)
} 


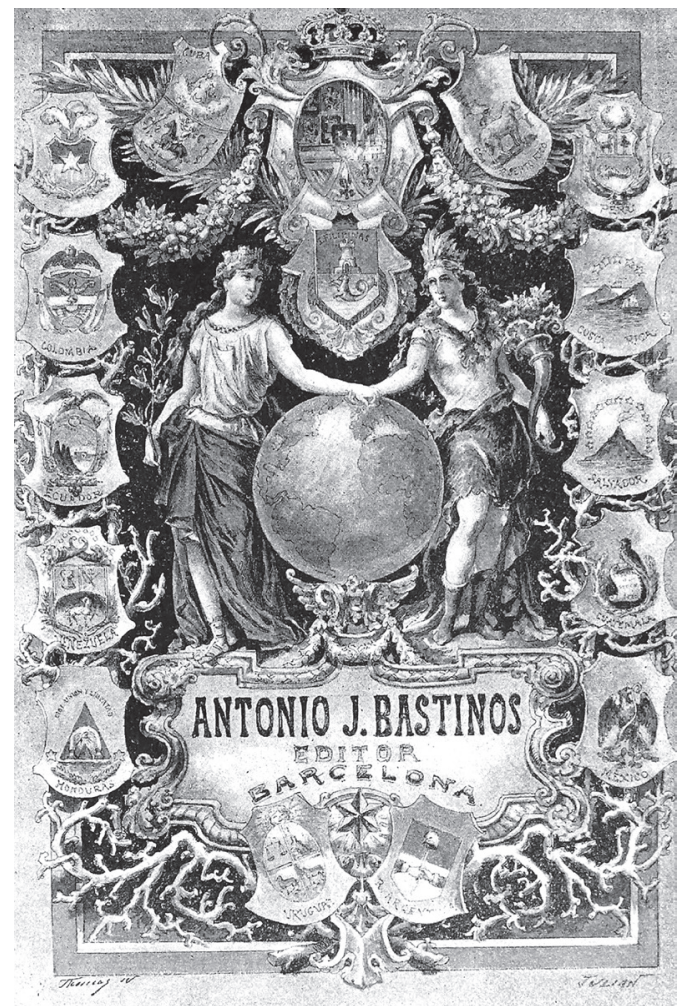

Figura 1. Portada del catálogo de Bastinos de 1897 con los escudos de las provincias de Cuba y Puerto Rico, y las de las repúblicas iberoamericanas de habla hispana.

En 1900, Bastinos publicó un catálogo con motivo de la Exposición Universal de París, lo editó en francés y era un extracto del catálogo principal. Recogía tanto referencias de libros como de material escolar. En las primeras páginas podemos leer historia de la casa comercial y ya encontramos referencias al material. Hablaba de que habían creado unos 2000 productos. Estos productos habían sido presentados en las Exposiciones en París, Zaragoza, Barcelona, Viena, Madrid, Santiago de Chile, Filadelfia, Matanzas, Villanueva, Lima, Burdeos y Chicago. Eran sus mercados principales además de la Península, Baleares y Canarias, las Repúblicas de México, Perú, Argentina, Uruguay, Nicaragua, Guatemala, Costa Rica, Honduras y Ecuador, las Islas Filipinas, las de Cuba y Puerto Rico. Hablaba explícitamente de los envíos a países de ultramar detallando bastante las condiciones de venta, tanto en español como en francés. ${ }^{49}$

${ }^{49}$ VV. AA., Extracto del Catálogo de los libros de enseñanza y material escolar del editor Antonio J. Bastinos: Exposición Universal de Paris de 1900 (Barcelona: Antonio J. Bastinos, 1900). 


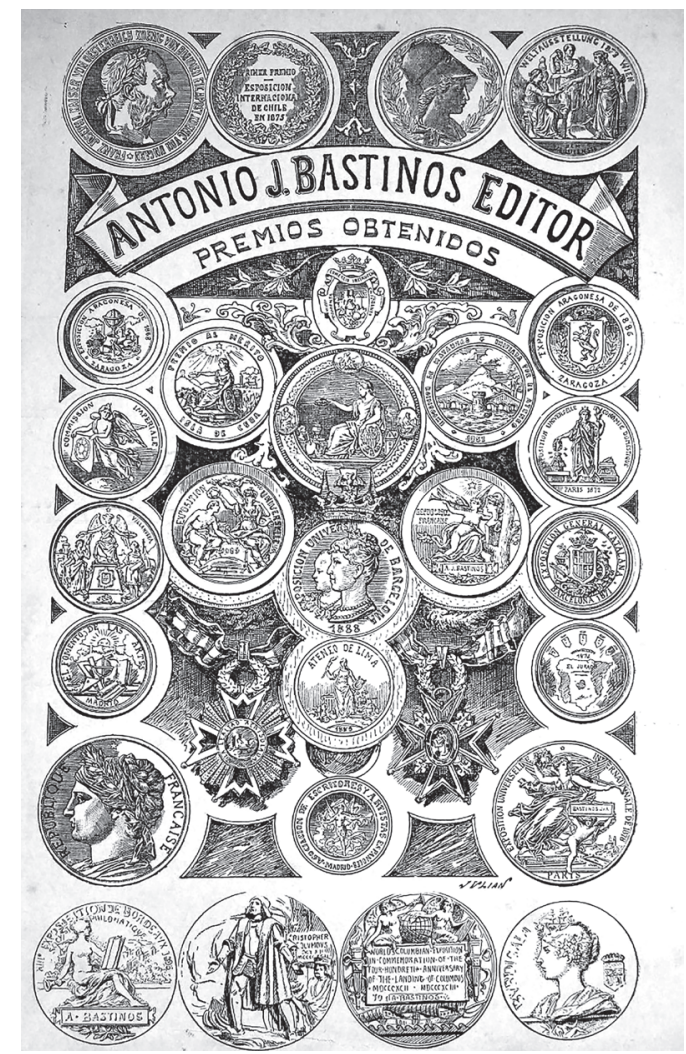

Figura 2. Catálogo Bastinos 1900. Exposiciones y Premios

En 1905 esta misma casa editorial publicó un nuevo catálogo, aunque el título es Librería Hispanoamericana Sucesores de Julián Bastinos. No hay referencia explícita al extranjero salvo en las letras que podían ser endosadas en Barcelona, Madrid o París. La casa comercial cambió su estrategia respecto a su expansión en el extranjero, pese a haber sido una de las primeras en explotar estos mercados, no pudo competir con las grandes compañías que entraron en juego con el inicio del siglo XX. ${ }^{50}$

La casa editorial Hernando fue fundada por Victoriano Hernando en 1828, la librería se especializó en edición escolar y proveía de material de enseñanza a distintos establecimientos madrileños. Destacan contratos con la Escuela Normal para dotar a las escuelas modelo que fueron abriendo en la capital. Así, es la librería Hernando quien dotó a la escuela modelo de los Jardines de la Infancia de Madrid del material necesario para poner en

${ }^{50}$ Librería Hispano-Americana Sucesores de Julián Bastinos, Catálogo General de las Obras de Primera Enseñanza de texto y consulta y material para escuelas (Barcelona: Imprenta de Francisco Badía,1905). 
marcha el método Fröbel. Para ello lo adquirió en la casa Bastinos de Barcelona, Hachette y com. de París y Hermann de Leipzig. ${ }^{51}$

En el catálogo de 1892 vemos como, al igual que Bastinos, especificaba que los precios consignados en el catálogo eran para Madrid. En cuanto a las condiciones había que pagar el pedido antes de recibirlo a través de giros o letras con sede en Madrid, Barcelona, París o Londres. El pago podía hacerse también en sellos de franqueo si las cantidades eran pequeñas. Dice literalmente "Los libreros de Ultramar y Repúblicas americanas vienen obligadas a remitir los fondos y siendo de su cuenta el quebranto o beneficio del cambio". Recomendaba hacer pedidos a través de corresponsales "con los cuales contamos en todas las provincias de España, posesiones de Ultramar y Repúblicas americanas". Detallaba los precios según el modelo de envío. Tras las condiciones de venta encontramos un prólogo a modo de presentación en el que se podía leer lo siguiente:

\begin{abstract}
A costa de perseverantes esfuerzos ha logrado que se abran a sus publicaciones los mercados americanos. Se horna con relaciones comerciales y amistosas con inteligentes e importantes hombres que se ocupan del comercio de librería, no menos que con distinguidos Profesores, y cuenta en el día con celosos corresponsales que propagan y extienden las producciones españolas en las repúblicas de Méjico, Chile, Perú, Venezuela, Guatemala, Costa Rica, Nicaragua, Honduras, San Salvador, Colombia, Ecuador, Argentina, Uruguay, etc... Se refiere a "pueblos hermanos que hablan el mismo lenguaje.
\end{abstract}

Apelaba a esa vinculación histórica como valor añadido y a continuación apuntaba: "Esto se funda en el empeño con que algunas naciones europeas y los Estados Unidos de América reimprimen con notables faltas y erratas nuestros libros". Y lo hacía en relación con el amplio mercado que Francia, Alemania y Estados Unidos dominaban en cuanto a la edición en castellano en los mercados hispanoamericanos. El catálogo contenía referencias a material y libros destinados a las escuelas de primera enseñanza. ${ }^{52}$

En 1894, dos años después, publicó un catálogo de material y libros de texto para Institutos, Escuelas Normales, seminarios y carreras especiales. Ampliaba la oferta más allá de la escuela primaria. Detallaba las mismas condiciones de venta que en el anterior catálogo y las condiciones de los pedidos a enviar por correo postal. Los pedidos pequeños recomendaba fueran encargados a los corresponsales y no directamente a la librería. En este catálogo ya no se hacía alusión directa al mercado hispanoamericano, a diferencia del anterior parece que estas regiones se habían consolidado como mercado a través de los corresponsales. Entre los materiales que ofertaba el catálogo podemos encontrar elementos fabricados en distintos países europeos, colecciones de Historia Natural publicadas en Alemania o mapas de casas francesas. Si bien la mayor parte de la producción era española, vemos como poco a poco, estas casas comerciales servían como distribuidoras de los materiales fabricados en países europeos, aunque hay que señalar que la

\footnotetext{
${ }^{51}$ Archivo General de la Administración, Caja 32/8776.

${ }^{52}$ Librería de la Viuda de Hernando y Cia., Catálogo del Material y efectos para las clases, libros de primera enseñanza y obras de consulta y de utilidad para los maestros (Madrid: librería de la Viuda de Hernando, 1892).
} 
producción española representaba aún un gran porcentaje de los materiales ofertados. ${ }^{53}$ Las condiciones de venta de la casa Hernando no cambiaron a lo largo del primer tercio del siglo XX y podemos ver reproducido el mismo texto en el catálogo de 1933 sin apenas variar esas alusiones. ${ }^{54}$ En este catálogo se referenciaban láminas editadas por Nathan. Si bien la mayoría de los materiales ofertados en el catálogo carecían de identificación en cuanto a la casa que los fabricaba. Hay algunos como el museo escolar fabricado para las escuelas españolas por la casa francesa Dorangeon.

La siguiente casa editorial analizada es Saturnino Calleja, concretamente el catálogo de 1911. Como nos ha apuntado Castellano ${ }^{55}$ es una de las pocas editoriales españolas que se posicionaron en el mercado iberoamericano en fechas tempranas. En este catálogo apreciamos varias alusiones a los mercados foráneos. La primera de ellas en la contraportada, un aviso que comenzaba con el siguiente texto: "Importante para nuestros corresponsales y para todos nuestros favorecedores de América, Alemania, Francia, Inglaterra e Italia". La editorial contaba con corresponsales en distintos países europeos además de en América, hecho que no es muy común entre las empresas españolas. A continuación de la llamada podemos leer una advertencia, escrita en todos los idiomas de los países citados, que informaba de que las obras del catálogo eran propiedad y publicadas por la editorial Calleja. ${ }^{56}$ Dos páginas más adelante encontramos que la empresa tenía cuenta corriente en distintas entidades bancarias radicadas en España, no solo españolas como el propio Banco de España, sino en otras como el Banco Hispanoamericano o el Alemán Trasatlántico de Madrid. Además de trabajar con los bancos nacionales de la mayor parte de las repúblicas iberoamericanas y con sucursales de entidades alemanas o inglesas que tenían oficinas en alguna de estas repúblicas. Las condiciones de venta, que contemplaban todo tipo de casuísticas, recogían un apartado especial referido a América y otros países. Este apartado, informaba al comprador extranjero que había de añadir una remesa de un $10 \%$ sobre el precio total para cubrir las fluctuaciones cambiarias, que, tras el cierre del negocio sería liquidada a favor de quien correspondiese.

Los materiales que ofertaban tanto este catálogo como el de 1922 de la misma editorial eran de fabricación propia. Se trataba de materiales que conformaban el ajuar del maestro, diplomas, plumas. No se oferta material didáctico científico más allá de los silabarios, por tanto, tal como anunciaban, todos los productos eran de fabricación propia. En el catálogo de 1922 vemos como las condiciones de venta ya no recogían instrucciones tan exhaustivas, sino que delegaba en los corresponsales los trámites de las transacciones. ${ }^{57}$

\footnotetext{
${ }^{53}$ Librería de la Viuda de Hernando y Cia., Catálogo de Material, libros de texto para institutos, escuelas normales y seminarios de carreras especiales (Madrid: Viuda de Hernando y Cia., 1894).

${ }^{54}$ Librería y Casa Editorial Hernando S.A., Catálogo de Material de Enseñanza y Mobiliario Escolar para toda clase de establecimientos docentes (Madrid: Imprenta de la Librería y Casa Editorial Hernando S.A., 1933).

${ }^{55}$ Castellano, "Francia, España, Hispanoamérica: Estrategias editoriales ante el mercado internacional del libro (1900-1914)"; Ruiz Berrio et al., La editorial Calleja, un agente de la modernización educativa en la restauración. ${ }^{56}$ Casa Editorial Saturnino Calleja Fernández, Catalogo agosto de 1911 (Madrid: Saturnino Calleja Fernández, 1911).

${ }^{57}$ Saturnino Calleja, Editorial Saturnino Calleja. Relación Extractada (Madrid: Saturnino Calleja, 1922).
} 
Los siguientes catálogos estudiados pertenecen a Librería Antonio Pérez de Madrid. El catálogo fechado en 1911, el más antiguo con el que contamos, se presentaba en primer término como Catálogo llustrado de Material de Enseñanza, dejando en segundo plano, al menos en el orden de citación, los objetos de escritorio, los libros y otros. ${ }^{58}$ Lo primero que se puede leer en el prólogo, dirigido a los señores profesores, es que tenían capacidad de servir cualquier producto que les encargase, ya que podían obtenerlo de "Autores, Editores y Casas Extranjeras". Es un catálogo centrado principalmente en la primera enseñanza. Apuntaba el propio Antonio Pérez que los artículos extranjeros estaban sujetos alteración de precios. Las condiciones de venta no eran muy exhaustivas, al contrario que en otros catálogos consultados.

El siguiente catálogo de la librería, fechado en 1930 recogía material procedente de distintas casas comerciales: mapas, láminas, aparatos de física, esferas terrestres, pesas y medidas. Es el que presentaba mayor número de referencias a ese potencial mercado que representaba Iberoamérica. Vemos ya, en la cubierta de esta lujosa edición, el anuncio de que la casa no tiene sucursales. Las condiciones de venta eran mucho más extensas que el anterior catálogo estudiado. A lo largo de sus 244 páginas presentaba todo tipo de enseres para la enseñanza, incluyendo mobiliario, y al igual que el anterior pero con mucha más variedad, incluía entre sus referencias, productos de diversas casas comerciales tanto españolas como extranjeras: francesas, alemanas y algunas otras sin especificar, sobre todo en lo referente a aparatos de física y química. ${ }^{59}$

Bazar Ibérico de Barcelona presentaba en $1915^{60}$ un magnífico catálogo de 460 páginas en una encuadernación en tapa dura, dedicado en exclusiva al material de enseñanza y destinado a todos los grados de la misma, desde la escuela elemental a las universidades. En cuanto al mobiliario se presenta como representante exclusivo de la American Seating Company, los modelos se encontraban recogidos al final del catálogo en un apartado independiente. En el apartado genérico podemos ver los modelos de pupitres aprobados por Museo Pedagógico Nacional. Aun siendo un catálogo que cuenta con un gran número de referencias, el prólogo no contenía advertencias ni condiciones de venta, se presentaba como una obra casi de consulta y cuyas condiciones probablemente se especificaban en folletos anexos u otros formatos que proporcionaban los representantes.

Perelló y Vergés se publicitaba como librería y casa editorial en la cubierta de su catálogo de $1915 .{ }^{61}$ Un catálogo general ilustrado de material de enseñanza y librería. En la contraportada encontramos la primera alusión a esa conexión alemana que estamos estudiando: podemos leer, "medalla de plata en la exposición de las artes del libro de Leipzig 1915 " En cuanto a las condiciones de venta mencionaba que concedían hasta seis meses

\footnotetext{
${ }^{58}$ Librería Escolar de Antonio Pérez, Catálogo Ilustrado de Material de Enseñanza, objetos de escritorio y dibujo; libros premios, obras religiosas etc....(Madrid: Hijos de Antonio Pérez, 1911).

${ }^{59}$ Hijos de Antonio Pérez, Catálogo llustrado de la Librería Escolar (Madrid: Hijos de Antonio Pérez, 1930).

${ }^{60}$ Bazar Ibérico, Catálogo General Ilustrado de Material Instructivo moderno para escuelas elementales y normales, institutos, universidades etc... (Barcelona: Material escolar y científico S.A., 1914).

${ }^{61}$ Perelló y Vergés, Catalogo General Ilustrado de Material de Enseñanza y Librería (Barcelona: Librería y Casa Editorial Perelló y Vergés, 1915).
} 
para el plazo de remesas en América y que los corresponsales en aquel continente estaban obligados a emitir fondos, corriendo de su cuenta el quebranto o beneficio del cambio. Designaba como representantes a sus corresponsales: Librería de España y Ultramar y los viajantes empleados de la misma. Se dedicaban a la primera enseñanza y comerciaban con productos de distintas casas españolas y extranjeras como el museo escolar Dorangeon, el mismo modelo y grabado que la casa Hernando.

Dalmau editorial fundada en Gerona en 1904 por Josep Dalmau Carles maestro por vocación, conocedor del sistema público de educación de la época, trató de llevar a esta escuela los métodos pedagógicos más vanguardistas. Intentando ir más allá puso en marcha su propia escuela y comenzó publicar sus propios textos. Salomó Marqués ${ }^{62}$ afirma que los catálogos de las publicaciones de la editorial Dalmau constituyen una nutrida fuente documental. La primera referencia de las relaciones con América data de 1904 y se trataba de una venta de libros. A final de los años 20 fue una de las primeras empresas españolas dedicadas a suministrar material escolar a distintos países de Iberoamérica, hecho que se puede apreciar en los catálogos. La editorial Dalmau basó su expansión comercial en la expansión en la modernización del material didáctico. ${ }^{63}$

El catálogo que hemos consultado es el de 1931-32. ${ }^{64}$ Se publicitaba con distintas medallas y diplomas conseguidos en diferentes partes del mundo, destacando por el tema que nos ocupa las conseguidas en Ecuador, Argentina o Cuba. En cuanto a las condiciones de venta vemos que los clientes de América contaban con un apartado especial en las mismas: "los clientes de América se ven obligados a hacernos fondos, a los clientes de América que prefieran pagar en francos (cheque sobre París), les abonaremos sus remesas al cambio corriente de los francos" Tenían cuentas corrientes en distintos bancos españoles y extranjeros, principalmente de capital francés. En el catálogo de 1935 vemos como ya no tienen cuenta en París. ${ }^{65}$ Encontramos al final de las condiciones de venta una llamada que pone:

Importante: Algunos de los artículos que figuran en el presente catálogo deben importarse de Francia. Debido a las posibles variaciones que pueden experimentar las partidas del arancel correspondientes a los artículos aludidos no podemos asegurar la fijeza de los precios cuando nos vamos precisados a importar nuevas partidas. Cuando un cliente interese un artículo cuyo precio forzosamente deba ser modificado se lo comunicaremos previamente esperando su confirmación para remitírselo.

\footnotetext{
${ }^{62}$ Salomó Marqués, "Dalmau Carles Pla: una editorial gerundense en sudamerica", en Historia de las relaciones educativas entre España y América (Sevilla: Universidad de Sevilla, 1988), 420-426.

${ }^{63}$ Josep González-Agápito, et al., Tradiciò i renovaciò pedagógica 1898-1939 (Barcelona; Institut d'estudis catalans, 2002).

${ }^{64}$ Dalmau Carles, Pla, Catalogo de Obras de la Casa Editorial Dalmau Carles, Pla S.A. Curso 1931-32. (Gerona: Dalmau Carles, Pla, 1931).

${ }^{65}$ Dalmau Carles, Pla, Catalogo de Material Escolar de la editorial Dalmau Carles, Pla. Curso 1935-1936 (Gerona- Madrid: Dalmau Carles, 1935).
} 
Los años florecientes de la casa Louis Michaud se remontan al periodo 1880-1910 aunque su origen es anterior. El catálogo estudiado es una obra de 620 páginas que podemos datar aproximadamente en 1913 aunque no presenta fecha de edición. ${ }^{66}$ Está encuadernado en tela y con el filo de las hojas decorado en pan de oro, lo que da idea del lujo de la edición que se vendía a un precio de 7'50 francos. El título: Catálogo ilustrado de materiales de educación moderna es un título abierto y que no se ciñe de forma específica ningún nivel educativo. La sociedad Ediciones Louis Michaud contaba con dos sedes: una en París y otra en Buenos Aires. El material ofertado, según anunciaban, estaba escogido especialmente para España, Portugal y las Repúblicas Ibero-Americanas. Se acompaña la portada con los escudos de la mayor parte de los países iberoamericanos; en el centro de la página vemos el escudo de Francia y flanqueado en sendos lados los escudos de España y Portugal junto a los que vemos los de Argentina y Brasil.

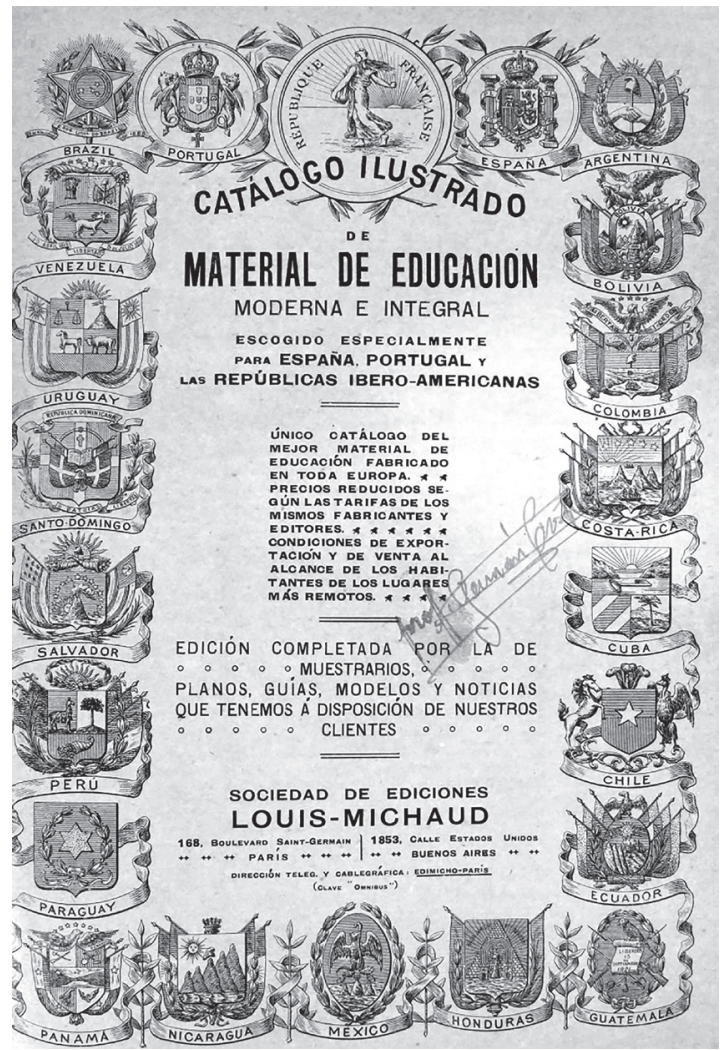

Figura 3. Portada interior del catálogo de material de educación Michaud con los escudos de Portugal, España y las repúblicas iberoamericanas y en posición central el símbolo de la república francesa.

${ }^{66}$ Louis Michaud, Catálogo llustrado de Material de Educación Moderna. (Paris -Buenos Aires: Sociedad de ediciones Louis-Michaud, 1914). 
A continuación podemos leer un comunicado de la Agrupación de Universidades y grandes escuelas de Francia para sus relaciones con Iberoamérica. Esta asociación fue creada en 1909 por iniciativa de los universitarios franceses para difundir en Iberoamérica los métodos pedagógicos y el pensamiento francés, durante el periodo entre guerras se centrará en establecer relaciones de cooperación científica con las repúblicas Iberoamericanas. ${ }^{67}$

Los artículos publicitados en el catálogo procedían de países europeos, no solo de Francia. Compraban directamente a productores para no tener intermediarios (comisionistas o exportadores). Apuntaban en las páginas introductorias que:

Hasta hace poco varias grandes casas germánicas habían dedicado poderosos esfuerzos a fomentar el empleo del material educativo especialmente publicado en Alemania, publicando catálogos en español, haciendo editar ediciones especiales en esta lengua y empleándolos para venderlos, numerosos agentes, particularmente en los pueblos de América del Sur y Central.

Seguía hablando de que el carácter alemán no era compatible con el latino, argumento este muy repetido en círculos pedagógicos españoles, apuntaba que había otros países que tendrían mayor afinidad con este carácter peculiar, dando cabida no solo a casas francesas sino a otras inglesas, belgas, suizas o suecas. En suma, un posicionamiento en el mercado en detrimento de la posición hegemónica que ocupaba Alemania con casas como K. F. Koehler o F. Volckmar que estudiaremos a continuación. Sin embargo podemos ver que, tanto en el texto que se cita como en la oferta de productos, en ningún momento se cierra la puerta a la comercialización de productos alemanes. Se puede considerar un guiño comercial más que un posicionamiento rígido.

En cuanto a las condiciones de venta especificaba cómo hacer los pedidos con destino a Iberoamérica, España y Portugal, cabe resaltar que Portugal y los países luxófonos solamente tuvieron cabida en este catálogo, aunque no podemos afirmar que no haya otros que los contemplen. Los pagos habían de hacerse en francos y el catálogo recogía, de forma desagregada y exhaustiva las condiciones de venta a 18 países americanos: precios de los fletes, embalajes, entidades financieras colaboradoras, plazos de entrega y una extensa relación de datos para cada uno de ellos. Este dato, junto con el precio de venta nos incita a señalar que puede ser una obra dirigida a comisionistas y representantes más que a establecimientos educativos o profesionales de la educación.

Sorprende que siendo un catálogo de material escolar publicita todo tipo de elementos mecánicos entre los que destacamos bicicletas, automóviles e incluso aviones; destacan también elementos de fontanería, construcción e incluso armas de fuego. Todos se encuentran incluidos en distintas secciones relacionadas con criterio pedagógico en las que se recomienda su utilización en establecimientos de enseñanza.

\footnotetext{
${ }^{67}$ Mona Huerta, "Un mediateur efficace pour la cooperation scientifique française: le groupement des universites et des grandes écoles de France pour les relations avec l'Amérique Latine". Encuentro de Latinoamericanistas Españoles (12. 2006. Santander): Viejas y nuevas alianzas entre Iberoamérica y España, 2006, s.l., Espagne. pp.792-803. ffhalshs-00103840f
} 


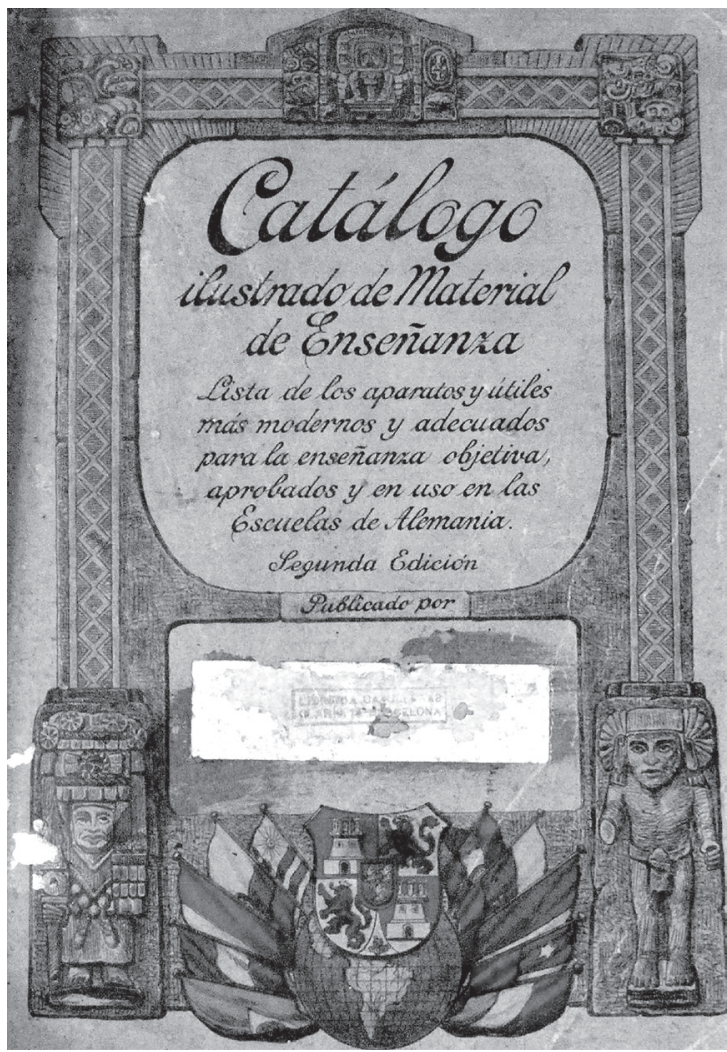

Figura 4. Portada del catálogo K.F. Koehler de 1910 en la que se aprecian todo tipo de elementos relacionados con Iberooamérica.

Karl Franz Koehler da su nombre a la casa editorial en 1830, el negocio se fue consolidando y fue aglutinando a otras editoriales alemanas. Como muchas empresas de este país se expandió y se posicionó en el mercado editorial americano. En 1888 tuvieron que abrir unos almacenes en Leipzig con objeto de tener género disponible para los comisionistas que trabajaban para ellos. A través del libro de texto y en relación con las disciplinas de ciencias cubrían una parte de la demanda que no contaba con proveedores especializados, dando al material didáctico un papel preponderante en la enseñanza de las ciencias según los nuevos métodos pedagógicos. K.F. Koehler en 1910 publicó una segunda edición de su catálogo de material de enseñanza. ${ }^{68}$ En la portada vemos el escudo de Castilla sobre un globo terráqueo centrado en el continente americano en el que se puede apreciar el

${ }^{68} \mathrm{~F}$. Koehler, Catalogo ilustrado de material de enseñanza. Lista de los aparatos y útiles más modernos y adecuados para la enseñanza objetiva, aprobados y en uso en las escuelas de Alemania. Segunda edición. 
sur de este continente. Alrededor de este punto central ondeaban recogidas las banderas de varios países iberoamericanos jalonados por dos estatuas que evocaban elementos de las culturas precolombinas. Se ensalzaba el sistema educativo alemán, aquí podemos ver el contrapunto de las notas del catálogo de Michaud en cuanto a la compatibilidad del carácter alemán con el carácter latino. Daba a entender que este método pedagógico, el alemán, de corte cientifista, y en suma los medios que utiliza, publicitados en el catálogo, eran los más vanguardistas del panorama educativo. Destacar que se trata de una edición especial española, aunque en estos catálogos, el que nos ocupa y los que estudiaremos a continuación, no encontramos alusiones a Portugal ni a los países de habla portuguesa. Destaca en el prólogo la extensa explicación que hacía acerca de los materiales destinados a las disciplinas de ciencias. Comercializaba todo tipo de marcas, la mayoría de ellas de fabricación alemana.

La casa comercial F. Volckmar fue heredera, al igual que Koehler de una larga tradición editorial que data de principios del siglo XIX en Leipzig. Esta editorial comenzó en 1887 a trabajar en la fabricación de material didáctico y se especializó en el área de ciencias. En 1901, al igual que Koehler hubo de hacerse con un almacén para tener género disponible para abastecer a los comisionistas que trabajaban para él y centralizar la distribución de distintos artículos. Vemos una estructura paralela en ambas editoriales que lleva a ambas compañías fusionarse en 1918 dando lugar a la compañía denominada Koehler \& Volckmar $A G(K V)$ radicada en la ciudad e Leipzig. ${ }^{69}$

F. Volckmar nos presenta en la portada de su catálogo de 1910 un estandarte en el que se cruzaban dos banderas españolas, sobre los soportes del estandarte ondeaban a ambos lados las banderas de distintos países latinoamericanos. El catálogo contenía un suplemento de libros de primera enseñanza. ${ }^{70}$ Podemos leer en el prólogo que en 1907 publicaron un catálogo ilustrado sobre materiales de enseñanza que se agotó en poco tiempo, era un catálogo dirigido a España y a América del Sur. Las instrucciones de los distintos aparatos habían sido traducidas al español. Los precios, al igual que en el catálogo de Koehler se expresaban en marcos. Este catálogo, al contrario que el anteriormente estudiado, presentaba las condiciones de venta de manera detallada. Los pagos podían hacerse en el Banco Alemán Trasatlántico que tenía sucursales en los distintos países de destino de las mercaderías. Los precios podían fluctuar según el mercado y una gran parte de los materiales ofertados eran los mismos que los relacionados en el catálogo de Koehler, aunque Volckmar presentaba productos de su propia marca además de los de otras casas comerciales.

\footnotetext{
69 Jürgen Voerster, Geschichte der Firmen: Koehler \& Volckmar (Stuttgart: Koch, Neff \& Volckmar, 2009)

${ }^{70} \mathrm{~F}$. Volckmar, Catálogo General de Material de Enseñanza y Útiles para escuelas.
} 


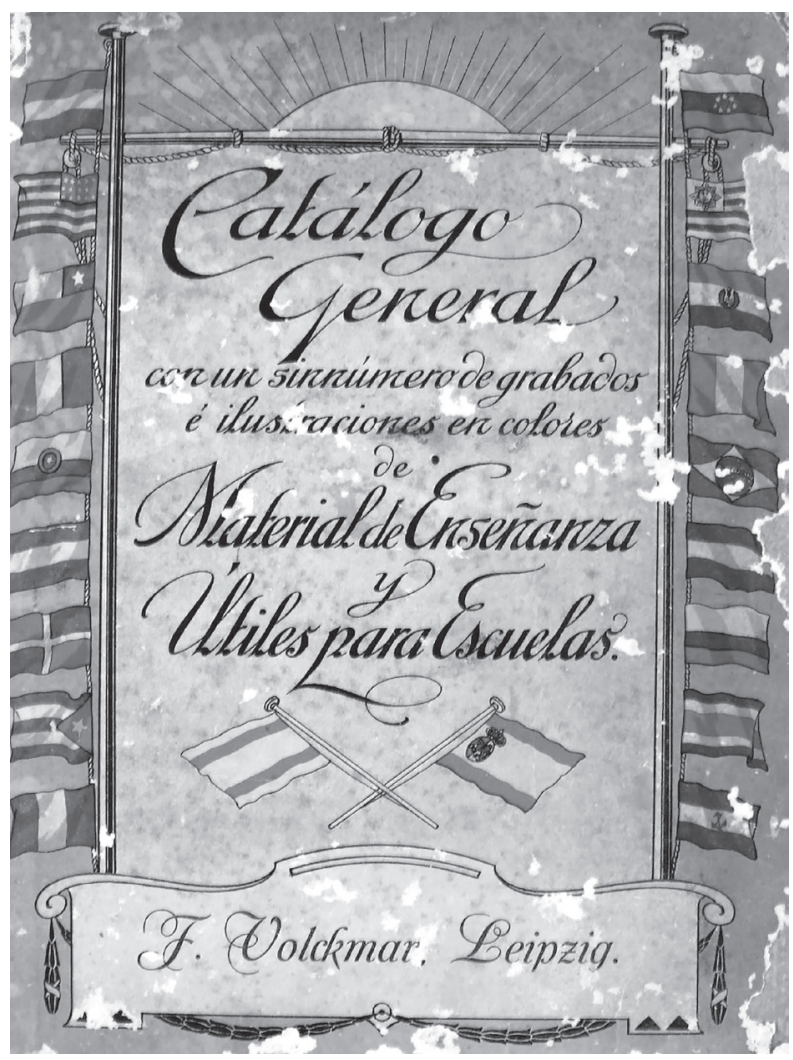

Figura 5. Portada del catálogo de la casa F. Volckmar de Leipzig con las banderas de los principales países iberoamericanos; destaca la presencia de Brasil y la ausencia de Portugal.

Ambas casas comerciales se fusionaron en una sola en 1918 Koehler \& Volckmar AG (KV) y de esta nueva compañía contamos con un catálogo publicado en $1928,{ }^{71}$ su título Catálogo General Ilustrado de Material Pedagógico Moderno. Material y utensilios seleccionados cuidadosamente para Escuelas Institutos Universidades de España y América Central y Meridional. La fusión tuvo lugar tras la I Guerra Mundial, en 1918, y el catálogo, según podemos leer la tercera edición del mismo, ve la luz en 1928, año en el que Alemania venía sufriendo las consecuencias de las reparaciones de guerra que se agravaron por la hiperinflación galopante que padecía su economía, sin dejar de mencionar aquí la crisis de superproducción, por lo que, aun siendo las mismas empresas que las que publican los catálogos anteriores las condiciones de venta eran diferentes.

${ }^{71}$ Koehler \& Volckmar A.-G. \& Co., Catalogo General Ilustrado de Material Pedagógico Moderno. 
La presentación gráfica de las portadas ha desaparecido, es sustituida por una tipografía más sobria, en el prólogo del catálogo se apuntaba que la situación económica era poco favorable y Alemania tenía restricciones en el mercado internacional, tanto de movilidad como crediticias. Calificaba como potenciales clientes a los países de habla hispana, apelaba al bajo precio de los materiales que se ofertan incluso manteniendo la calidad, debido a la devaluación de la moneda alemana. Destacaba las disciplinas de ciencias y los materiales didácticos destinados a las mismas como su producto estrella. Advertía de que los precios no eran estables. Hablaba de talleres, es decir fabricación propia, estas casas comerciales que vendían y distribuían los productos de otras fábricas se convirtieron en fabricantes. Los productos que fabricaban, montaban o almacenaban en Leipzig, se comercializarán bajo el sello KV. Se trataba de dar salida a una gran cantidad de productos que abarrotaban sus almacenes, se buscaban mercados capaces de consumir esa producción y, ante la posición desfavorable de Alemania en el contexto mundial, se utilizaba a España como garante de las transacciones.

Este catálogo no contenía precios, sino que los productos se ordenan por referencias numéricas. Contaba con un anexo en el que, a partir de estas referencias, se detallaban los precios en marcos (Reichmark RM) con un cambio fijo que venía determinado por el Dólar-oro americano como referencia estable. Los precios solo tenían validez mientras el aumento del coste de producción no obligase a modificarlos.

\section{Conclusiones}

El material escolar es subsidiario del comercio editorial, utiliza las vías que establecieron las editoriales entre Europa e Iberoamérica, son un desarrollo de estas líneas que comienzan a ponerse en marcha con la edición de libros de texto. El despegue de los sistemas educativos en Iberoamérica presenta cierto desfase respecto a Europa, esta coyuntura hace que los productores europeos vean el sur del continente americano como un enorme mercado a conquistar.

De la mano del desarrollo de este mercado, en Europa tenía lugar un movimiento, la Escuela Nueva, que postula que el aprendizaje se produce a partir de la experimentación. Para ello son necesarios elementos manipulables. Las casas editoriales comienzan ofertando material de escritorio, útiles y diplomas. Más tarde serán las láminas y los mapas, elementos de fácil trasporte y que pueden ser enviados por correo postal. El correo postal entre España e lberoamérica es objeto de condiciones especiales durante el periodo estudiado, lo que favorece los intercambios.

Estos primeros contactos comerciales irán aumentando y algunas casas editoriales españolas trasformaran parte de sus recursos, sino todos, para dar respuesta a la demanda que se establecía desde las nacientes burguesías. Pero no solo las casas españolas, como hemos visto en el estudio contextual, el posicionamiento de casas editoriales tanto francesas como alemanas en el mercado iberoamericano data de mediados del siglo XIX y cuenta con una red de distribución consolidada. Dicha red servirá de soporte a las casas comerciales francesas y alemanas, entre otras, para introducir sus productos en este nuevo mercado. 
A partir de 1905 aproximadamente las grandes casas comerciales alemanas y francesas comienzan a explotar sistemáticamente este mercado utilizando a España como plataforma. En un primer momento a través de corresponsales y posteriormente sirviéndose de las propias redes que las casas españolas tenían establecidas en las diferentes republicas. La afinidad lingüística con España, en el caso francés también con el mercado portugués: las ventajas arancelarias; la posibilidad en el caso de Alemania de comerciar esquivando las reparaciones y los contactos comerciales establecidos en base a otros negocios, hacen de España o España y Portugal, una plataforma óptima para la conquista de los mercados iberoamericanos por parte de las grandes casas de material escolar del continente europeo.

Destaca especialmente la posición alemana en cuanto al desarrollo del material científico orientado a la enseñanza. Cada país se especializará en un campo, así Estados Unidos, y aun no siendo objeto de este estudio, tiene en el mobiliario escolar su producto más extendido, Francia se apoyará en el libro de texto para, como hemos visto en el catálogo de Michaud, comerciar con todo tipo de mercaderías.

Se hace necesario un análisis en profundidad de estos aspectos que exceden a la dimensión del trabajo que aquí se presenta. Apuntar que hacia 1935 o quizá antes, este papel de España como intermediario o facilitador con el mercado de los países iberoamericanos desaparece, ya que las tensiones del periodo entreguerras reestructuran los flujos comerciales de esta parte del mundo.

Como afirma Wollon, ${ }^{72}$ existen diferentes modos de interpretación de los modelos educativos dependiendo del elemento o elementos trasmisores y del contexto de recepción. Estos hechos dan lugar a modificaciones que con el tiempo definen un nuevo modelo y lo dotan de identidad propia. La comercialización de materiales dibuja flujos que informan de esas trasferencias y de los modelos educativos que subyacen y que se hacen patentes a través del material didáctico.

\section{Bibliografía}

Archivo General de la Administración, Caja 32/8776

Balsameda de González, Joaquina et al., Almanaque Bastinos para 1885. Barcelona: Librería de Juan y Antonio Bastinos, 1884.

Bastinos, Antonio J. Catálogo Ilustrado de los Productos de esta Casa. Libros y Material Escolar. Barcelona: Antonio J. Bastinos Editor, 1897.

Bazar Ibérico, Catálogo General Ilustrado de Material Instructivo moderno para escuelas elementales y normales, institutos, universidades etc... Barcelona: Material escolar y científico S.A., 1914.

\footnotetext{
${ }^{72}$ Roberta Wollons (ed.), Kindergarten and Cultures: The Global Diffusion of an Idea, (New Haven: Yale University Press, 2000).
} 
Bellotti, Elisa. Qualitative Networks. Mixed Methods in Sociological Research. New York: Routledge, 2015.

Bosch, José. Centenario de la Librería Bastinos. Barcelona: José Bosch, 1952.

Botrel, Jean-Francois. "La cultura escrita en España (1833-1936): Balance y perspectivas". Revista brasileira de História da Mídia, 2 (2015):11-23.

Botrel, Jean-Francois. "Los libreros y las librerías. Tipología y estrategias comerciales". En Historia de la edición en España, dirigida por. Jesús A. Martínez Martín, 135-164. Barcelona: Marcial Pons, 2001.

Brunelli, Marta. "Posibles metodologías de trabajo histórico sobre la cultura material de la escuela: entre el material didáctico y los catálogos de enseñanza - Primeros resultados de una investigación en curso". En Cultura material escolar em perspectiva histórica: escritas e posibilidades, (org) V. Gaspar. G. de Souza, C. Castro, 181-215. Vitória: Edufes, 2018.

Calduch Cervera, Rafael. "La estructura económica internacional del siglo XIX". Estudios Internacionales de la Complutense vol. 8, 3 (2006): 35-81.

Calleja, Saturnino. Editorial Saturnino Calleja. Relación Extractada. Madrid: Saturnino CaIleja, 1922.

Casa Editorial Saturnino Calleja Fernández, Catalogo agosto de 1911. Madrid: Saturnino Calleja Fernández, 1911.

Castellano, Philippe. "Francia, España, Hispanoamérica: Estrategias editoriales ante el mercado internacional del libro (1900-1914)". Cahiers de civilisation espagnole contemporaine, 2 (2015).

Ceballos, Álvaro. "La implantación de la librería alemana en España e Hispanoamérica de 1850 a 1900". En Handeln und Verhandeln. Beiträge zum 22. Nachwuchskolloquium der Romanistik, editado por Marina HERTRAMPF et al., 453-472. Bonn: Romanistischer Verlag, 2007.

Ceballos, Álvaro. "Las empresas editoriales de Jose Abelardo Núñez en Alemania, 18811905", Historia, 41, vol I (2008): 43-62

Compagnon, Olivier. "Influences? Modèles? Transferts culturels? Les mots pour le dire". América: Cahiers du CRICCAL, 33 (2005): 11-20.

Dalla Corte, Gabriela y Espósito, Fábio. "Mercado del libro y empresas editoriales entre el Centenario de las Independencias y la Guerra Civil española: la editorial Sudamericana". Revista Complutense de Historia de América, 36 (2010): 257-286.

Dalmau Carles Pla. Catalogo de Material Escolar de la editorial Dalmau Carles, Pla. Curso 1935-1936. Gerona- Madrid: Dalmau Carles, 1935. 
Dalmau Carles Pla. Catalogo de Obras de la Casa Editorial Dalmau Carles, Pla S.A. Curso 1931-32. Gerona: Dalmau Carles, Pla, 1931.

Dussel, Inés. "Between exoticism and universalism: educational sections in Latin American participation at international exhibitions, 1860-1900". Paedagogica Historica, 47 (2011): 601-617.

Espagne, Michel. "La notion de transfert culturel”. Revue Sciences/Lettres, 1 (2013)

Esteban, León. "Los catálogos de librería y material de enseñanza como fuente iconográfica y literario-escolar". Historia de la Educación, 16 (1997):17-46

Fernández Moya, María. "Editoriales españolas en Iberoamérica. Un proceso de internacionalización secular". Información Comercial Española, ICE: Revista de economía, 897 (2009), 67-77.

Fernández Moya, María. "Multinacionales del castellano. El proceso de internacionalización del sector editorial español". Revista de historia industrial, 40 (2009): 23-50.

Fernández, Pura. "El monopolio del mercado internacional de impresos en castellano en el siglo XIX: Francia, España y 'la ruta' de Hispanoamérica”. Bulletin Hispanique, tome 100, 1, (1998): 165-190.

Fernández, Pura. "La editorial Garnier de París y la difusión del patrimonio bibliográfico". En Tes philies tade dora: miscelánea léxica en memoria de Conchita Serrano, 603-612. Madrid: CSIC, 1999.

González-Agápito, Josep et al. Tradiciò i renovaciò pedagógica 1898-1939. Barcelona; Institut d'estudis catalans, 2002.

Guereña, Jean Louis. "La edición escolar en España durante la Restauración (18751900)". En Centros y periferias: prensa, impresos y territorios en el mundo hispánico contemporáneo: homenaje a Jacqueline Covo-Maurice, coord. Nathalie Ludec y Françoise Dubosquet Lairys, 105-116. París: PILAR, 2004.

Haenggeli-Jenni, Béatrice, Alexandre Fontaine et Patrick Bühler, "Une circulation des saviors pédagogiques sur papier. Revues pédagogiques, transfertset trajectoires transnationalesdes savoirs (1850-2000)", Revue suisse des sciences de l'éducation 36,1 (2014): 11-15.

Hijos de Antonio Pérez, Catálogo llustrado de la Librería Escolar. Madrid: Hijos de Antonio Pérez, 1930.

Huerta, Mona. "Un mediateur efficace pour la cooperation scientifique française: le groupement des universites et des grandes écoles de France pour les relations avec l'Amérique Latine". Viejas y nuevas alianzas entre Iberoamérica y España. XII Encuentro de Latinoamericanistas Españoles, 792-803. Santander: Consejo Español de Estudios Iberoamericanos, 2006. 
Koehler \& Volckmar A.-G. \& Co., Catalogo General Ilustrado de Material Pedagógico Moderno. Material y utensilios seleccionados cuidadosamente para escuelas, Institutos y Universidades de España y de América Central y Meridional. Leipzig, Alemania: Koehler \& Volckmar A.-G. \& Co, 1928.

Koehler, K. F. Catalogo ilustrado de material de enseñanza. Lista de los aparatos y útiles más modernos y adecuados para la enseñanza objetiva, aprobados y en uso en las escuelas de Alemania. Segunda edición. Leipzig: K.F. Koehler, 1910.

Larraz, Fernando. Una historia trasatlántica del libro. Relaciones editoriales entre España y América latina (1936-1950). Madrid: Trea, 2010.

Librería de la Viuda de Hernando y Cia. Catálogo de Material, libros de texto para institutos, escuelas normales y seminarios de carreras especiales. Madrid: Viuda de Hernando y Cia., 1894.

Librería de la Viuda de Hernando y Cia. Catálogo del Material y efectos para las clases, libros de primera enseñanza y obras de consulta y de utilidad para los maestros. Madrid: librería de la Viuda de Hernando, 1892.

Librería Escolar de Antonio Pérez, Catálogo Ilustrado de Material de Enseñanza, objetos de escritorio y dibujo; libros premios, obras religiosas etc.... Madrid: Hijos de Antonio Pérez, 1911.

Librería Hispano-Americana Sucesores de Julián Bastinos, Catálogo General de las Obras de Primera Enseñanza de texto y consulta y material para escuelas. Barcelona: Imprenta de Francisco Badía, 1905.

Librería Juan y Antonio Bastinos, Catálogo de los efectos y libros propios de la casa. Barcelona: Juan y Antonio Bastinos, 1881.

Librería y Casa Editorial Hernando S.A. Catálogo de Material de Enseñanza y Mobiliario Escolar para toda clase de establecimientos docentes. Madrid: Imprenta de la Librería y Casa Editorial Hernando S.A., 1933.

López-Morell, Miguel A. y Molina Abril, Alfredo. "La compañía iberoamericana de publicaciones, primera gran corporación editorial en castellano". Revista de historia industrial, 49 (2012): 111-145.

Marín, Jose P. y Martínez, Ma José. "Categorización de los materiales didácticos para la enseñanza de los seres vicos en los antiguos gabinetes y laboratorios", Cabás, 21 (2019): 1-22.

Marqués, Salomó. "Dalmau Carles Pla: una editorial gerundense en sudamerica". En Historia de las relaciones educativas entre España y América, 420-426. Sevilla: Universidad de Sevilla, 1988. 
Martínez Ruiz-Funes, M.J. "Los catálogos de material escolar como fuente para el estudio de la cultura material: la recepción y difusión del Método Froebel en España". En Patrimonio y Etnografía en España y Portugal durante el siglo XX, editado por P.L. Moreno, A. Sebastián, 265-277. Murcia: SEPHE y CEME, 2012.

Martínez Rus, Ana. "Comercio de libros. Los mercados americanos". En Historia de la edición en España, dirigida por Jesús A. Martínez Martín, 269-305. Barcelona: Marcial Pons, 2001.

Martínez Rus, Ana. "La industria editorial española ante los mercados americanos del libro 1892-1936", Hispania 212 (2002): 1021-1058

Meda, Juri. Mezzi di Educazione di Massa. Saggi di Storia della Cultura Materiale della Scuola tra XIX e XX Secolo. Milano: Franco Angeli, 2016.

Michaud, Louis. Catálogo Ilustrado de Material de Educación Moderna. Paris -Buenos Aires: Sociedad de ediciones Louis-Michaud, 1914.

Millán, Jose Antonio. "Separados por un mismo idioma, el mercado del libro español". Letras libres 165 (2015).

Moreno, Pedro L. y Marín, Jose P. "La casa comercial Cultura y la oferta de Material Pedagógico Moderno en España (1924-1934)". En Pedagogía museística. Prácticas usos didácticos e investigación del patrimonio educativo, (coords.) A. Badanelli, M. Poveda Sanz, C. Rodríguez, 523-531. Madrid: Universidad Complutense de Madrid, 2014.

Morilla Ortíz, José. La crisis económica de 1929. Madrid: Pirámide, 1988.

Ossenbach, Gabriela. Corrientes e instituciones educativas contemporáneas. Madrid: UNED, 2012.

Ossenbach, Gabriela. Formación de los sistemas educativos nacionales en Hispanoamérica: el caso ecuatoriano, 1895-1912. Quito: Universidad Andina Simón Bolivar 2018.

Perelló y Vergés, Catalogo General Ilustrado de Material de Enseñanza y Librería. BarceIona: Librería y Casa Editorial Perelló y Vergés, 1915

Ruiz Berrio, Julio et al. La editorial Calleja, un agente de la modernización educativa en la restauración. Madrid: UNED, 2002.

Sánchez Vigil, Juan Miguel. "La editorial CALPE y el catálogo general de 1923". Documentación de las ciencias de la información, 29 (2006): 259-277;

Smeyers, Paul and Depaepe, Marc. Educational Research: Material Culture and its Representation. Swizerland: Springer, 2014.

Thorp, Rosemary. Pobreza, progreso y exclusión. Una historia económica de Iberoamérica en el siglo XX. Washington DC: Banco Interamericano de desarrollo, 1998. 
Tirado Fabregat, Daniel A. “Crecimiento económico (1870-1913): Internalización y cambio tecnológico". En Los tiempos cambian. Historia de la economía, edición de Jordi Palafox, 141-170. Valencia: Tirant lo Blanch, 2014.

Voerster, Jürgen. Geschichte der Firmen: Koehler \& Volckmar. Stuttgart: Koch, Neff \& Volckmar, 2009.

Volckmar, F. Catálogo General de Material de Enseñanza y Útiles para escuelas. Leipzig: F. Volckmar, 1910.

V. AA. Extracto del Catálogo de los libros de enseñanza y material escolar del editor Antonio J. Bastinos: Exposición Universal de Paris de 1900. Barcelona: Antonio J. Bastinos, 1900.

Wollons, Roberta (ed.), Kindergarten and Cultures: The Global Diffusion of an Idea. New Haven: Yale University Press, 2000. 